\title{
Propionic acidemia
}

INSERM

\section{Source}

INSERM. (1999). Orphanet: an online rare disease and orphan drug data base. Propionic acidemia. ORPHA:35

Propionic acidemia (PA) is an organic aciduria caused by the deficient activity of the propionyl Coenzyme A carboxylase and is characterized by life threatening episodes of metabolic decompensation, neurological dysfunction and that may be complicated by cardiomyopathy. 